\title{
Conditions for collaboration between higher education and healthcare providers organising clinical placements
}

Ann-Charlotte Bivall, Maria Gustavsson and Annika Lindh Falk

The self-archived postprint version of this journal article is available at Linköping University Institutional Repository (DiVA):

http:/ / urn.kb.se/ resolve?urn=urn:nbn:se:liu:diva- 172364

N.B.: When citing this work, cite the original publication.

Bivall, A., Gustavsson, M., Lindh Falk, A., (2020), Conditions for collaboration between higher education and healthcare providers organising clinical placements, Higher Education, Skills and Work-based Learning. https:// doi.org/ 10.1108/ HESWBL-09-2020-0201

Original publication available at:

https:// doi.org/ 10.1108/HESWBL-09-2020-0201

Copyright: Emerald

http:/ / www.emeraldinsight.com/ 


\title{
Conditions for Collaboration between Healthcare Education and Healthcare Providers Organising Clinical Placements
}

\author{
Ann-Charlotte Bivall, Maria Gustavsson and Annika Lindh Falk \\ Linköping university
}

\begin{abstract}
Purpose - Clinical placement is an important formalised student activity for linking healthcare education and healthcare practices. The purpose of this study is to investigate the organising of clinical placements by examining conditions for collaboration between higher education and healthcare organisations.
\end{abstract}

Design/methodology/approach - The study is based on interviews with central actors at a university and two healthcare organisations with official duties of organising clinical placements.

Findings - The findings show that collaboration in the organising of clinical placements is a complex matter of interconnected actors in different organisational positions, at both strategic and operative levels. The university and the healthcare organisations approached the clinical placement with a shared commitment.

Practical implications - The findings provide important guidance for improving collaboration in the organising of clinical placements. This may have an impact on how contextual conditions of the educational framing and daily healthcare practices are viewed and how the interdependency between the long-term strategic issues and the short-term needs of healthcare organisations is approached. 
Originality - This research emphasises the need for careful consideration of the collaborative practices on an organisational level between higher education and healthcare organisations as different needs, motives and logics have to be considered.

Keywords - clinical placement; healthcare higher education; education and workplace collaboration

Paper type - Research paper

\section{Introduction}

Clinical placements have the potential to contribute to the overall quality of medical and healthcare higher education as they allow students to enhance their academic performance and gain real work experience (Scully, 2011). An important condition to ensure the quality and success of clinical placements stems from a close collaboration between higher education institutions and healthcare organisations. Previous research underlines an interdependency between educational and professional practices in healthcare (Murray, Borneuf and Vaughan, 2005; Pepin et al., 2017). This includes, for example, providing a foundation for linking theoretical and practical aspects of healthcare programmes, ensuring that course content corresponds with professional practices, workforce planning and recruitment, and facilitating the transition between academic education and professional working life. A close relationship between educational and professional practices thus seems paramount to ensure sustainable quality in medical and healthcare education (Barnett et al., 2008; Bvumbwe, 2016; Taylor et al., 2015).

Although quality measures vary, making assessment a delicate matter (Bergseth, Petocz and Abrandt Dahlgren, 2014), there has nonetheless been a focus on issues of quality in clinical placements in previous research. Research has focussed on the 
carrying through of placements, for example from the students' perspectives and perceptions of support, reflection and engagement (Kettis et al., 2013; Nisbet et al., 2020; Peters, Halcomb and McInnes, 2013; Smith and Martin, 2014). However, in this study we move the focus to an organisational level of analysis, namely the organising of clinical placements between higher education institutions and healthcare organisations. Although collaboration between higher education and healthcare organisations is regarded as highly important to succeed when educating qualified healthcare professionals (Frenk et al., 2010), the nature and status of collaboration has been questioned. Voices of concern have been raised in connection with ensuring that universities preserve their independent position and remain uncompromised by labour market demands (Arthur, Brennan and de Weert, 2007). In raising such matters, it becomes apparent that while both universities and organisations in the healthcare sector do share educational concerns, they differ in their strategic missions. De Geest and colleagues (2010) suggest that the establishment of economic frameworks and incentives for collaboration are important as a ground for collaboration, but do not in themselves create constructive collaborative practices. Rather, organisational engagement at all levels in healthcare organisations, shared commitment and acknowledgement of the need for collaboration are needed to achieve productive collaboration (De Geest et al., 2010; Reeve and Gallacher, 2005). Despite the best intentions for collaboration, differences in organisational cultures may impair the understanding of goals and values and the understanding of knowledge and learning (Reeve and Gallacher, 2005; Garraway, 2010). Higher education institutions and healthcare organisations have different needs and challenges in meeting the changes that appear continuously in the healthcare system, such as a transition to person-centred care, difficulties recruiting professional staff and reductions in resources (Fox and 
Reeves, 2015). There is thus a potential range of tensions in the collaborative practices between universities and healthcare organisations.

Despite the complexities surrounding collaborative efforts between higher education and healthcare organisations, the underlying interdependency shapes the relationship when it comes to clinical placements. Higher education is dependent on healthcare organisations in terms of placement capacity (Barnett et al., 2008; Murray and Williamson, 2009) and quality and healthcare organisations rely on higher education programmes to provide qualified staff with an understanding of everyday work practices including patient care and safety - to which clinical placement periods contribute (e.g. Pollard et al., 2007). The parties thus share common concerns when it comes to organising qualitative clinical placements for students (Taylor et al., 2015). This paper aims to investigate the organising of clinical placements by examining the conditions for collaboration between higher education institutions and healthcare organisations. The paper draws on evidence from a Swedish study based on interviews with central actors from a university and two healthcare organisations with official duties that involve organising clinical placements.

In the analysis, the focus is primarily on the conditions for collaboration between the university and healthcare organisations when organising student clinical placements in education programmes for medical and healthcare professions. Clinical placement is an important formalised activity that links healthcare education and workplaces, in which the requirements from both parties must be considered in order to integrate disciplinary and work-based knowledge to ensure that students fulfil the programmes' professional learning outcomes (Evans and Guile, 2012). The amalgam of disciplinary and work-based knowledge in educational curricula states the expected requirements for entering a specific profession, based on academic and work-based 
performance. Clinical placement serves as a bridge to develop coherent education programmes that address both academic and working life requirements (Evans and Guile, 2012; Garraway, 2009).

\section{Theoretical framework}

In this paper, the organising of clinical placements and the close collaborative relationship between higher education and healthcare organisations is informed by Evans and Guile's (2012) theoretical framework, later developed by Gustavsson and Persson Thunqvist (2018). This theoretical framework focuses on the interrelated connections and processes, and tensions, between education and workplace contexts (see also Billett, 2011; Schaap, Baartman and de Bruijn, 2012). Contexts are not just understood as places; they have a broader meaning that include thoughts, traditions and norms shaping the specific features of the context (Evans et al., 2010). In the theoretical model, the mutual interrelatedness of the educational and workplace contexts is emphasised. Evans and Guile's (2012) seminal work does not particularly focus on the organisational level of the organising of work-based learning activities, such as clinical placements, but they argue that it is necessary to develop a coherent curriculum with a good balance between contextual requirements when organising professional education programmes. Based on the above referenced theoretical framework, this paper takes a slightly different stance by focusing on the organising of clinical placements in the overlapping space between central actors who have to consider the requirements of both the healthcare education institution and the workplace (see Figure 1).

Figure 1. The relationship between the educational and workplace contexts (modified from Gustavsson and Persson Thunqvist, 2018, p. 7).

In educational programmes that rely largely on work-based elements such as clinical 
placements, both disciplinary and work-based knowledge shape the educational programmes' curricula and influence work-based elements which are organised between the educational and workplace contexts. The alliance between educational and workplace contexts is formed by common agreements on what can be offered in the collaboration and what is expected of the other party (Henderson, Heel and Twentyman, 2007). In relation to clinical placements, this includes quality assurance, financial compensation and the number and duration of student placements. Collaboration and alliances between educational institutions and workplaces have been problematised (Gibbs and Armsby, 2010). In the healthcare literature, the close relationship between educational and workplace contexts emerges in the form of challenges and barriers that highlight a reciprocal association and a need for collaboration. Universities provide employers with health professionals when students graduate. For this to happen, the healthcare organisations must host students during work-based elements of programme courses. However, challenges regarding capacity issues and planning have been pointed out as problematic (Barnett et al., 2012; Magnusson, O’Driscoll and Smith, 2007; Murray and Williamson, 2009; Taylor et al., 2015), not least as clinical placement periods often are determined by the academic year with peaks of students present in the workplaces rather than an even distribution over the calendar year (Hutchings, Williamson and Humphreys, 2005). Nisbet and colleagues (2020) problematise such an educational foundation in the organising of clinical placement by showing that collaboration between educational institutions and healthcare organisations benefited from taking an organisational point of departure in their collaborative discussions. Nevertheless, health service organisations must meet the university's educational requirements to provide workplaces that deliver high-quality learning experiences for the students. The function of clinical supervisors for student learning is paramount in 
the literature on practice placement success, but studies also point out the need for further support and development for healthcare staff with a supervising role (Dobrowolska et al., 2016; Kirke, Layton and Sim, 2007; Rodger et al., 2008). A lack of recognition for the work of taking on and mentoring students might otherwise lead to shortages of supervisors (Kirke, Layton and Sim, 2007; Maloney, Stagnitti and Schoo, 2013). Furthermore, in the daily care practice, the professionals are required to balance between sometimes competing demands of delivering care on the one hand, and on the other, focussing on the students' learning and development, resulting in needs of temporary focus prioritisation and supervision strategies (Pront, Gillham and Schuwirth, 2016). There are thus numerous challenges concerning the educational and workplace relationship, collaboration and quality management.

As such, the educational and workplace contexts represent and focus attention on different requirements which are to be considered in the organising of clinical placements. The theoretical model by Evans and Guile provides a basis for understanding collaboration and its conditions at an organisational level, where requirements from both university and workplaces must be considered when organising clinical placements within professional education programmes.

\section{Material and method}

The study we report on here is part of a large research project aimed at contributing knowledge of interprofessional learning arrangements during clinical placements. This paper particularly focuses on organising students' clinical placements, which takes place in collaboration between a university's faculty of medicine and health sciences and two healthcare organisations (one regional provider for hospital and primary care and one municipal social and healthcare provider). All organisations were located in central Sweden. At the national level, Swedish universities are responsible for 
implementing the system of qualification outlined in the Higher Education Ordinance (HSF, 1993:100) which involves the university being accountable for students' education and, thus, the organising of clinical placements. This is accomplished in collaboration with regional and municipal healthcare providers in a shared education mission. In the studied organisations, agreements regulated each party's undertakings in organising clinical placements such as financial issues, quality expectations, the number of students involved and the duration of clinical placements.

\section{Design and selection of participants}

This study has a qualitative research design consisting of nine individual interviews with eight strategically chosen informants from the three participating organisations. The eight informants were selected because they held key positions in their respective organisations with official duties that involved organising student clinical placements. The three informants from the university were the vice dean of the faculty and the clinical placement coordinators for the allied health and nursing programmes and the medical programme. The five informants from the healthcare organisations were two clinical placement development leaders, a clinical placement director for allied health and nursing, a clinical placement coordinator and a clinical lecturer. As joint organisers of the clinical placements, the selected key informants provided rich detailed descriptions of organising clinical placements. Thus, in our judgement, the seemingly small sample provides enough data for a credible analysis.

\section{Data collection}

Nine individual interviews were conducted with eight informants from the three participating organisations. One informant was interviewed twice as the organisation was in the midst of a major organisational change that affected the clinical placements. 
The purpose of the interviews was to obtain information about how clinical placements were organised between the university and the healthcare organisations and to explore a wide variety of perceptions of challenges and conditions related to collaborations in organising clinical placements. The informants received information about the research project in advance and gave informed consent to participate in the interviews. The interviews were held at the informants' workplaces and lasted approximately 60 minutes. Two of the authors conducted the interviews which were guided by a semistructured interview guide. The interview guide included three main topics: 1) how student clinical placements were organised, 2) challenges the informants encountered and dealt with while arranging clinical placements, and 3) conditions that enabled or constrained collaboration within and between organisations. The interviews were akin to conversations and the informants talked openly, giving examples during the interviews which provided illustrative descriptions of the issues in focus. The interviewers asked follow-up questions in connection to the informant's descriptions to fully understand the answers. The interviewers also encouraged the informants to carry out a deeper analysis of the descriptions they passed on by asking 'how' and 'why'. All interviews were recorded digitally and transcribed verbatim.

\section{Data analysis}

The interviews were transcribed verbatim. In the first step of the analysis, all interview transcripts were read and re-read for familiarisation. Joint analytical discussions were carried out within the research team to gain a broader understanding of the interviews. Coding was carried out, inspired by qualitative content analysis (Schreier, 2014), resulting in categorisations of different ways of organising clinical placements and conditions for collaboration in clinical placements between the university and the two healthcare organisations. This part of the analysis was guided by the theoretical model 
framing this paper (Evans and Guile, 2012; Gustavsson and Persson Thunqvist, 2018), focusing on the relationship between the higher education and workplace contexts, which has to be considered in order to understand the different parties' conditions for collaboration when organising clinical placements. In the content analysis, two main patterns emerged from the material: challenges and conditions were found at strategic and operative levels concerning the organising of clinical placements and collaboration between the university and the healthcare organisations. At the strategic level, the challenges and conditions related to formalised issues between the organisations, while at the operative level, the focus was on operational execution and anchoring students at workplaces in the two healthcare organisations.

\section{Findings}

\section{Organising clinical placements between the university and the healthcare organisations}

The organising of clinical placements in the two healthcare organisations was complex, resulting in the university having to adapt to the healthcare organisations' differing internal structures and routines for handling students' clinical placements. The differences in organising the clinical placements had led to multiple ways and levels of collaboration between the university and the two healthcare organisations. One result of this complexity was the institutionalisation of two different forums for collaboration: one that involved the university and the municipal social and healthcare provider, and one that involved the university and the regional healthcare provider (see Figure 2). The forums took the form of formal meetings on a regular basis throughout the year. The meetings were led by the vice dean of the faculty and involved appointed central representatives from the organisations. Although not the sole topic of the meetings, 
clinical placement was a regular point on the agenda and involved discussing strategic issues such as financial agreements, educational and curriculum quality criteria, supervisor competence and the availability of workplaces for student clinical placements. The main objective of these forums as described in the interviews was to negotiate the common undertaking of organising qualitative clinical placements.

Figure 2. Institutionalised forums bridging the educational and workplace contexts.

The structure of having separate forums for the healthcare organisations meant that all parties never came together at the same time. This was described as stemming from a traditional view of the differences between healthcare practices within the regional healthcare provider and the municipal social and healthcare provider. However, this divide was regarded a missed opportunity for the municipal and regional healthcare providers to learn from one another as they, at least to some degree, struggled with the same issues when providing clinical placements. For more profound changes in the organising and execution of clinical placements, for example meeting changing directions of care, collaboration between all parties was pointed out as a more forceful approach.

\footnotetext{
It's not enough that we in the municipalities sit and talk and have a dialogue with the medical faculty, and then the medical faculty has that same dialogue with the regional healthcare provider. We need a triad where everyone needs to participate in order to achieve some development in this. (Municipal 4)
}

The need for more formal ways of collaborating was also seen in the institutionalisation of a specific position, that of clinical lecturer. While this position was a shared arrangement between the regional provider and the university, the position was dormant 
at the municipal social and healthcare provider at the time of the interviews. The clinical lecturer entailed working half-time at the university and half-time at the regional provider. Work tasks for the clinical lecturer within the university related to professionspecific competencies; that is, the idea of contributing working life experience to educational activities. In the regional setting, the clinical lecturer collaborated closely with managers and healthcare staff, with a focus on quality issues relating to clinical placements such as supervision development. The role of the clinical lecturer was seen as a possibility for connecting the educational and healthcare settings, "so that we're not regarded as two different worlds and then we never meet", as one of the university informants expressed it. The knowledge and understanding of both contexts thus formed a basis for collaboration and the development of clinical placements.

And perhaps now we're going into a... new phase... where we have greater possibilities to influence, we might need that from our organisational point of view. And then I again want to highlight the clinical lecturers who have so much knowledge about both [organisations] so that it's invaluable for the planning and formation of the future clinical placement. They are a gold mine. (Regional 2)

We have now described the formal organisation of collaboration concerning clinical placements, which in itself constitutes a precondition for collaboration between the university and the healthcare organisations. As we will show in the following analysis, there were also other conditions that enabled or constrained collaboration between the parties. At the strategic level, the challenges and conditions involved formalised issues between the organisations, while at the operative level, the focus was on the execution of clinical placements at workplaces within the healthcare organisations.

\section{Conditions for collaboration at a strategic level}

In the interviews, awareness emerged of an interdependency between the organisations 
and how such an interrelatedness constituted a basis for collaboration while also directly forming it. The healthcare organisations could, for example, find it necessary to make changes in the students' educational curricula for the clinical placements as they were deemed difficult to address in the practical setting or would benefit from being updated in relation to changed professional practices. The informants showed awareness of how such changes would imply lengthy institutional decision-making processes at the university, but that changes could also be necessitated by developments in healthcare. The collaborative relationship was here based on a shared understanding of institutional and contextual conditions. Having knowledge about the other context facilitated discussions and decision-making, although it was not the solution to dilemmatic development issues. Different change logics made it necessary to discuss and envision future strategic developments long in advance to meet the conditions of the bureaucratic university. As the pace and decision-making processes in the healthcare organisations are characterised by much shorter cycles, there was always a possibility that by the time of change they would already be outdated. Long-term and short-term changes thus had to be balanced between what could be achieved within set limits (such as curricula and agreements) and what could be achieved in relation to contextual set-ups.

A condition that was particularly prominent in the interviews was the continuous need to deal with logistical placement issues. In the periods before students' clinical placements, issues of managing larger number of students from the different professions occupied the collaborative space.

There are so many students, in total. It's such a great mass that logistically has to be there [in the practices] and has to be able to function. (Municipal 4)

The number of students enrolled on the educational programmes varied from semester to semester, making long-term planning of supervisors and placements difficult for the 
healthcare organisations. The anticipated number of students could be changed at short notice, creating uncertainty on wards and at units regarding whether or not the students would actually arrive.

You decide on a number of placements and then we find those placements in our organisation... but it becomes a burden for supervisors and the organisation when you plan for students who then don't come. So, all the time, this is a balance we work with a lot, my colleague and I at the medical faculty. (Regional 2)

Additionally, the informants described how the possibility to receive students could be impaired by organisational changes, such as reductions in beds or staff eligible to work as supervisors. Cutbacks and reorganisations of wards and units on short notice could make it difficult or even impossible to receive a previously agreed number of students. The placing of students constituted a significant condition for collaboration, as it involved managing different contexts, supervisors, healthcare staff, students and so on.

But it's a bit hard to look forward when there are so many actors involved. On the one hand we have the organisation that suddenly finds itself without staff or nurses or patient beds, and then we have the education where they have accepted ' $X$ ' number of students. So, it's a lot about this day-to-day work. (Regional 2)

Logistical placement issues necessitated on-the-go solutions, impairing long-term planning and the development of clinical placements, although this was also on the agenda.

Well it's difficult... to make developments because we're kind of solving... this semester's problems, and then we solve the next semester's problems and then we solve the next semester's problems, and I'm talking about placements and that stuff. (Municipal 3)

Another condition for collaboration was having networks and personal connections with key individuals. The informants underlined how their work depended on good 
individual relationships that were established and lasted over time. Knowing who to work with enabled collaboration between and within organisations. It simplified dealing with tasks as the informants could lean on previous dialogues, solutions and actions. Relying and depending on personal relationships for constructive collaboration was however also seen as a potential risk, as staff changes made long-term collaborative relationships vulnerable. Functional contact routines are related to personal connections and are a condition for collaboration, as there are so many people involved in the clinical placements. The university and the regional healthcare provider had developed organisational structures to simplify communication and collaboration across the organisations. By establishing central coordinators at the organisations, they created liaisons that facilitated contact with the appropriate people.

\section{Conditions for collaboration at an operational level}

In relation to planning for and implementing clinical placements in the daily practices, other conditions for collaboration emerged.

Knowledge of contextual and organisational frames were acknowledged by the informants as providing possibilities for acting within their limits and offering opportunities for small-scale collaborative and explorative clinical placement activities.

\footnotetext{
If you have an idea you want to test on your clinical placement but it doesn't affect the days and it doesn't affect where the students are, maybe you want to try a different pedagogical format, then I think the way to do it has to be short so you can try it out fairly simply and pretty instantly. (University 1)
}

Implementing incubatory activities was encouraged at a central level within the organisations, as shown in the quotation above. At an operational level in the healthcare settings, however, first-line managers and their views on and attitudes towards students and clinical placements were decisive for the scope of collaborative activities. The 
interviews showed that not all managers were positive towards clinical placements and taking on students, leading to barriers to collaborative activities and local clinical placement initiatives from supervisors. Managers with a more positive attitude towards clinical placements promoted student learning activities and supervisor initiatives for organising student learning activities. Also, a beneficial view promoted other collaborative activities related to clinical placements, such as staff development through interaction and activities with students, and the future recruitment of staff.

\section{Discussion}

The findings of this study show that collaboration in the organising of clinical placements is a complex matter of interconnected actors in different organisational positions. The joint collaborative mission, as regulated by agreements, was to provide students with theoretical and practical knowledge to meet future staff needs in the healthcare sector. Following this premise, clinical placements were managed as a shared commitment between the university and the two healthcare organisations. Quality concerns were as an intrinsic part of their daily discussions, but were also explicitly expressed as a logistical problem to ensure that students gained access to workplaces providing high-quality learning experiences and supervision to achieve the curriculum of clinical placements. It was necessary to co-produce the organising of clinical placements, but the findings demonstrated that this was conditioned by the parties' different missions, such as the university's delivery of quality healthcare education, and the healthcare organisations' delivery of quality care. As our findings suggest, in line with other studies, a balancing act emerged between the organisational contexts' different conditions and interests that required active collaboration to achieve goals stipulated in the healthcare programmes (Billett, 2011; Evans et al., 2010). The theoretical model (Evans and Guile, 2012; Gustavsson and Persson Thunqvist, 2018) 
underpinning the present study allows us to discern the interrelatedness between higher education and healthcare organisations, and the conditions for collaboration created at different levels in the organisations. The conditions operated, as our findings indicate, on both the university and the healthcare sides and at both strategic and operative levels in the organisations. This is what creates the collaborative complexity in organising clinical placements and underlines a need to scrutinise how collaboration is established and furthered between the parties.

As a way of discerning the interplay between higher education and healthcare when arranging work-based educational elements, Brandt and colleagues (2008) suggest an analytical division between the content of collaboration and the degree of formalisation of such activities. Despite the existence of regulated and financial agreements between the university and the healthcare organisations, the interviewed central actors did not suggest that they guided the collaborative relationship. Rather, formalised forums, roles and communication channels played important roles in the continuous work and the development of clinical placements. Such systemised structures and meetings provided continuous possibilities over time for collaboration concerning both short-term and long-term issues between the university and the healthcare organisations. Access to good opportunities for communication have proved to be important for collaborative relationships concerning clinical placements (Henderson, Heel and Twentyman, 2007). It is, however, interesting to note how the university collaborated with the municipal and regional healthcare providers separately, as parallel tracks, although the healthcare organisations shared many of the same concerns regarding collaborative efforts and challenges in the organising and development of clinical placements. One interpretation of this is that the regional healthcare provider had been an important collaborative partner for many years, 
whereas structured collaboration with the municipal social and healthcare provider had developed more recently. The differences in the healthcare organisations permeated the collaboration and formed conditions for joint activities, depending on traditions and cultures in the overlapping spaces of collaboration in their relationships with the university. Such issues are important to understand when arranging formalised forums for collaboration at organisational levels to link different partner organisations' requirements and develop productive collaborations (De Geest et al., 2010; Reeve and Gallacher, 2005).

At the strategic level there were also conditions other than formalised forums. The strategic development and management of clinical placements was achieved through collaborative discussions across central levels in the organisations in an iterative process moving between the educational setting and the healthcare organisations (Nisbet et al., 2020). A major condition for accomplishing qualitative clinical placements and developing healthcare educations was dealing with the large number of students. This pressing issue demanded intense collaboration, and a great deal of time was devoted to finding eligible workplaces and placing students in them. The strategic conditions for collaboration had practical operational implications at the workplaces. Although the central actors recognised that the healthcare organisations actively collaborated to deliver qualitative clinical placements, it was striking how the everyday healthcare work practice conditions were prioritised and influenced whether and how the clinical placements could be provided. As previous research has shown, organisational conditions and changes such as high workloads, staff reductions, reductions in beds and shortages of supervisors have great significance for the possibility to receive students and carry out clinical placements (Kirke, Layton and Sim, 2007). Taking departure in the workplace organisations' everyday issues and concerns 
thus seem highly important in discussion the joint effort of clinical placement (Nisbet et $a l ., 2020)$. However, if the first-line managers in the healthcare settings had a positive approach towards clinical placements, it was easier to place students. Engaged managers seemed to support local developmental initiatives and saw no barriers to clinical placements, although they struggled with everyday work.

Different change logics at the university and the healthcare organisations were also important conditions for collaboration in the organising of clinical placements. Implementing long-term changes was constrained by rigid bureaucratic conditions at the university, for example when changing clinical placement curricula. The problem recognised by the central actors was that the practices pursued different parallel pathways. Change occurred more frequently and in shorter production cycles at the healthcare organisations, where ordinary work activities continued regardless of how the clinical placements were organised. The healthcare organisations seemed to have difficulties adapting to the inflexible conditions of the university's management and development of clinical placements. However, adjustments in clinical placement curricula had implications for organising and carrying out of clinical placements at the healthcare organisations. An awareness and understanding of the counterparty's modus operandi provided the right conditions for collaboration and was present in both directions between the university and the healthcare organisations. In that sense, the clinical lecturer had an important role in bridging contextual differences between the university and the workplaces. The clinical lecturers thus took on the function of a broker who "forge[d] relationships between theory, sector-wide knowledge and the practices of particular organisations and particular people within those organisations" (Evans et al., 2010, p. 250). The clinical lecturers seemed to be an important bridge between the educational and workplace contexts, bringing work practice experience into 
the educational context and vice versa. This means that the clinical lecturers' experiences of both the education and workplace practices can be used as a collaborative resource when organising clinical placements.

\section{Conclusion and implication}

The study provides important guidance for organising clinical placements. Despite deriving from a small dataset, the conclusion is that collaborative organising of clinical placements featured great complexity that involved both the strategic and operational levels in higher education and healthcare organisations. Collaboration about quality issues was based on a continuous dialogue between the different parties at both central and local levels. The actuality of more practical concerns on the floor was repeatedly accounted for and pointed to the close relationship between higher education and healthcare organisations. Organising clinical placements cut across educational and workplace contexts and entailed an active orientation towards defining quality concerns in both types of organisations (university and healthcare) and how to ensure meaningfulness in the collaboration process and, ultimately, for students. In order to be able to ensure students' practice learning, it was stressed that changes in educational knowledge content, in terms of requests from clinical practices or initiatives from educational institutions, spanned both sides and the consequences thereof impacted both parties.

The findings are pertinent for the organising of clinical placements as a shared commitment between higher education and healthcare organisations. The study illustrates why and how the organising of clinical placement between the university and healthcare organisations may be a decisive condition for bridging theoretical knowledge and practical application, preparing students for professional careers. 
A potential criticism, however, is that our study omits the analysis of the use of national regulators that set standards for healthcare educations, professional bodies' roles and how they regulate the requirements of professional competence, and what impact these aspects have on the organising of clinical placement. A further and more comprehensive investigation of organising clinical placements could include such aspects of regulations; it is however necessary to consider national variations and policy changes over time. The contribution of this study is therefore foremost to point out the need to consider the interrelatedness and contextual conditions of the educational framing and daily healthcare practices in dealing with the long-term strategic issues and the short-term needs of both parties to improve the organising of clinical placements, and thereby also quality of education.

\section{References}

Arthur, L., Brennan, J. \& de Weert, E., 2007, 'Employer and higher education perspectives on graduates in the knowledge society. A report from the European Commission Framework VI project: The Flexible Professional in the Knowledge Society' (London, The Open University).

Barnett, T., Cross, M., Jacob, E., Shahwan-Akl, L., Welch, A., Caldwell, A. \& Berry, R., 2008, 'Building capacity for the clinical placement of nursing students', Collegian, 15(2), pp. 55-61.

Barnett, T., Walker, L.E., Jacob, E., Missen, K., Cross, M.D. \& Shahwan-Akl, L., 2012, 'Expanding the clinical placement capacity of rural hospitals in Australia: Displacing Peta to place Paul?', Nurse Education Today, 32(5), pp. 485-89.

Bergseth, B., Petocz, P. \& Abrandt Dahlgren, M., 2014, 'Ranking quality in higher education: Guiding or misleading?', Quality in Higher Education, 20(3), pp. $330-47$.

Billett, S., 2011, Vocational Education: Purposes, traditions and prospects (Dordrecht, Springer).

Brandt, E., Dæhlen, M., Hagen, A., Hertzberg, D., Kaloudis, A., Seip, Å.A., Storen, L.A., Thune, T. \& Vabo, A., 2008, Effekter av samarbeid mellom høyere 
utdanning og arbeidsliv - en forstudie [The impact of cooperation between higher education and workplaces - A preliminary study]. Fafo-notat 2008:11. Oslo: Fafo and NIFU STEP.

Bvumbwe, T., 2016, 'Enhancing nursing education via academic-clinical partnership: An integrative review', International Journal of Nursing Sciences, 3(3), pp. 31422.

De Geest, S., Sullivan Marx, E.M., Rich, V., Spichiger, E., Schwendimann, R., Spirig, R. \& Van Malderen, G., 2010, 'Developing a financial framework for academic service partnerships: Models of the United States and Europe', Journal of Nursing Scholarship, 42(3), pp. 295-304.

Dobrowolska, B., McGonagle, I., Kane, R., Jackson, C.S., Kegl, B., Bergin, M., ... Palese, A., 2016, 'Patterns of clinical mentorship in undergraduate nurse education: A comparative case analysis of eleven EU and non-EU countries', Nurse Education Today, 36, pp. 44-52.

Evans, K., Guile, D., Harris, J. \& Allan, H., 2010, 'Putting knowledge to work: A new approach', Nurse Education Today, 30(3), pp. 245-51.

Evans, K. \& Guile, D., 2012, 'Putting different forms of knowledge to work in practice', in Higgs, J., Barnett, R., Billett, S., Hutchings, M. \& Trede, F. (Eds.) Practice-Based Education: Perspectives and strategies (Sense Publishers, Rotterdam)

Frenk, J., Bhutta, Z. A., Chen, L. C.-H., Cohen, J., Crisp, N., Evans, T., ... PablosMendez, A., 2010, 'Health professionals for a new century: Transforming education to strengthen health systems in an interdependent world', The Lancet, 376(9756), pp. 1923-58.

Gibbs, P. \& Armsby, P., 2010, 'Higher education quality and work-based learning: Two concepts not yet fully integrated', Quality in Higher Education, 16(2), pp. 18587.

Garraway, J., 2010, 'Knowledge boundaries and boundary-crossing in the design of work-responsive university curricula', Teaching in Higher Education, 15(2), pp. 211-22.

Garraway, J.W., 2009, 'The role of difference in the creation of work-responsive curriculum units', Higher Education Research and Development, 28(6), pp. 57184. 
Gustavsson, M. \& Persson Thunqvist, D., 2018, 'Students' vocational learning: Enabling conditions for putting knowledge to work', in McGrath, S., Mulder, M., Papier, J. \& Suart, R. (Eds.) Handbook of Vocational Education and Training: Developments in the changing world of work (Springer)

Henderson, A., Heel, A. \& Twentyman, M., 2007, 'Enabling student placement through strategic partnerships between a health-care organisation and tertiary institutions', Journal of Nursing Management, pp. 91-96.

Högskoleförordningen [The higher education ordinance] HSF, 1993:100

Hutchings, A., Williamson, G.R. \& Humphreys, A., 2005, 'Supporting learners in clinical practice: Capacity issues', Journal of Clinical Nursing, 14(8), pp. 94555.

Kettis, Å., Ring, L., Gustavsson, M. \& Wallman, A., 2013, 'Placements: An underused vehicle for quality enhancement in higher education?', Quality in Higher Education, 19(1), pp. 28-40.

Kirke, P., Layton, N. \& Sim, J., 2007, 'Informing fieldwork design: Key elements to quality in fieldwork education for undergraduate occupational therapy students', Australian Occupational Therapy Journal, 54(S1), pp. 13-22.

Magnusson, C., O’Driscoll, M. \& Smith, P., 2007, 'New roles to support practice learning - Can they facilitate expansion of placement capacity?', Nurse Education Today, 27(6), pp. 643-50.

Maloney, P., Stagnitti, K. \& Schoo, A., 2013, 'Barriers and enablers to clinical fieldwork education in rural public and private allied health practice', Higher Education Research and Development, 32(3), pp. 420-35.

Murray, C., Borneuf, A.M. \& Vaughan, J., 2005, 'Working collaboratively towards practice placements', Nurse Education in Practice, 5(3), pp. 127-28.

Murray, S.C. \& Williamson, G.R., 2009, 'Managing capacity issues in clinical placements for pre-registration nurses', Journal of Clinical Nursing, 18(22), pp. 3146-54.

Nisbet, G., McAllister, S., Morris, C. \& Jennings, M., 2020, 'Moving beyond solutionism: Re-imagining placements through an activity systems lens', Medical Education, pp. 1-10.

Pepin, J., Goudreau, J., Lavoie, P., Bélisle, M., Blanchet Garneau, A., Boyer, L., Larue, C. \& Lechasseur, K., 2017, 'A nursing education research framework for 
transformative learning and interdependence of academia and practice', Nurse Education Today, 52, pp. 50-52.

Peters, K., Halcomb, E.J. \& McInnes, S., 2013, 'Clinical placements in general practice: Relationships between practice nurses and tertiary institutions', Nurse Education in Practice, 13(3), pp. 186-91.

Pollard, C., Ellis, L., Stringer, E. \& Cockayne, D., 2007, 'Clinical education: A review of the literature', Nurse Education in Practice, 7(5), pp. 315-22.

Pront, L., Gillham, D. \& Schuwirth, L.W.T., 2016 'Competencies to enable learningfocused clinical supervision: A thematic analysis of the literature', Medical Education, 50(4), pp. 485-495.

Reeve, F. \& Gallacher, J., 2005, 'Employer-university “partnerships”: A key problem for work-based learning programmes?', Journal of Education and Work, pp. 219-33.

Rodger, S., Webb, G., Devitt, L., Gilbert, J., Wrightson, P. \& McMeeken, J., 2008, 'Clinical education and practice placements in the allied health professions: An international perspective', Journal of Allied Health, 37(1), pp. 53-62.

Schaap, H., Baartman, L. \& de Bruijn, E., 2012, 'Students' learning processes during school-based learning and workplace learning in vocational education: A review', Vocations and Learning, 5(2), pp. 99-117.

Schreier, M., 2014, 'Qualitative content analysis', in Flick, U. (Ed.) The SAGE Handbook of Qualitative Data Analysis (London, SAGE).

Scully, N.J., 2011, 'The theory-practice gap and skill acquisition: An issue for nursing education', Collegian, 18(2), pp. 93-98.

Smith, S. \& Martin, J., 2014, 'Practitioner capability Supporting critical reflection during workbased placement - A pilot study', Higher Education, Skills and Work-based Learning, 4(3), pp. 284-300.

Taylor, M.A., Brammer, J.D., Cameron, M. \& Perrin, C.A., 2015, 'The sum of all parts: An Australian experience in improving clinical partnerships', Nurse Education Today, 35(2), pp. 297-303. 